Abstract P1-S2.40 Table 1 HIV coinfection among men who had sex with men (MSM) in the past 12 months with primary and secondary (P\&S) syphilis, by age group, race, and ethnicity-34 states, 2009

\begin{tabular}{|c|c|c|c|c|c|c|c|c|}
\hline \multirow[b]{2}{*}{$\begin{array}{l}\text { Age group, } \\
\text { years }\end{array}$} & \multicolumn{2}{|l|}{ Black MSM } & \multicolumn{2}{|c|}{ Hispanic MSM } & \multicolumn{2}{|l|}{ White MSM } & \multicolumn{2}{|l|}{ Other MSM } \\
\hline & $\begin{array}{l}\text { With P\&S } \\
\text { syphilis, no. }\end{array}$ & $\begin{array}{l}\text { HIV coinfected, } \\
\text { no. }(\%)\end{array}$ & $\begin{array}{l}\text { With P\&S } \\
\text { syphilis, no. }\end{array}$ & $\begin{array}{l}\text { HIV coinfected, } \\
\text { no. }(\%)\end{array}$ & $\begin{array}{l}\text { With P\&S } \\
\text { syphilis, no. }\end{array}$ & $\begin{array}{l}\text { HIV coinfected, } \\
\text { no. }(\%)\end{array}$ & $\begin{array}{l}\text { With P\&S } \\
\text { syphilis, no. }\end{array}$ & $\begin{array}{l}\text { HIV coinfected, } \\
\text { no. }(\%)\end{array}$ \\
\hline $15-19$ & 219 & 77 (35\%) & 62 & $7(11 \%)$ & 49 & $11(22 \%)$ & 10 & $1(10 \%)$ \\
\hline $20-24$ & 728 & 377 (52\%) & 252 & $76(30 \%)$ & 227 & $61(27 \%)$ & 41 & $9(22 \%)$ \\
\hline $25-29$ & 485 & $315(65 \%)$ & 258 & $113(44 \%)$ & 288 & $115(40 \%)$ & 48 & $20(42 \%)$ \\
\hline $30-34$ & 296 & $201(68 \%)$ & 202 & $102(50 \%)$ & 272 & $140(51 \%)$ & 39 & $18(46 \%)$ \\
\hline $35+$ & 676 & $454(67 \%)$ & 487 & $315(65 \%)$ & 1512 & $854(56 \%)$ & 93 & $51(55 \%)$ \\
\hline Total & 2404 & 1424 (59\%) & 1261 & 613 (49\%) & 2348 & 1181 (50\%) & 231 & 99 (43\%) \\
\hline
\end{tabular}

USA during 2009 and $77 \%$ of estimated HIV diagnoses during 2008. Of 6501 men who had sex with men (MSM) in the past 12 months with P\&S syphilis, 6346 (98\%) were asked about HIV status-53\% were coinfected with HIV, $38 \%$ were not coinfected, $1 \%$ refused to disclose their status, and $8 \%$ did not know their status. Across all regions, prevalence of HIV coinfection among MSM with P\&S syphilis was high (51-55\%, depending on region). Black MSM with P\&S syphilis were younger than other MSM with P\&S syphilis-39\% of black MSM with P\&S syphilis were under 25 years old (Hispanic MSM-25\%, white MSM-12\%, other MSM-22\%) (see Abstract P1-S2.40 Table 1). Compared to 15-19-year old and 20-24year old MSM with P\&S syphilis of other races and ethnicities, black MSM were more likely to be HIV coinfected (RR 15-19-year old $=2.2, \mathrm{p}<0.001$; RR 20-24-year old $=1.8, \mathrm{p}<0.001)$. Prevalence of HIV coinfection increased with age; black MSM with P\&S syphilis reached the highest prevalence of HIV coinfection at an earlier age than MSM with P\&S syphilis of other races and ethnicities.

Conclusion Regardless of race, ethnicity or region, MSM with P\&S syphilis had high rates of HIV coinfection. Interventions at young ages are urgently needed to prevent HIV and P\&S syphilis among MSM.

\section{P1-S2.41 SENTINEL SURVILLANCE FOR PHARYNGEAL CHLAMYDIA AND GONORRHOEA AMONG MEN WHO HAVE SEX WITH MEN - SAN FRANCISCO, 2010}

doi:10.1136/sextrans-2011-050108.98

${ }^{1} \mathrm{~J}$ Park, ${ }^{2} \mathrm{~J}$ Marcus, ${ }^{2} \mathrm{~K}$ Bernstein, ${ }^{2} \mathrm{M}$ Pandori, ${ }^{2} \mathrm{~A}$ Snell, ${ }^{2} \mathrm{~S}$ Philip. ${ }^{1} \mathrm{UC}$ Berkeley, Berkeley, USA; ${ }^{2}$ San Francisco Department of Public Health, USA

Background Although a potentially important route for transmission, limited data exist on the burden of pharyngeal chlamydia (CT) and gonorrhoea (GC) among men who have sex with men (MSM). The San Francisco Department of Public Health has recommended nucleic acid amplification test (NAAT)-based pharyngeal screening for MSM since 2005. We examined pharyngeal CT and GC among MSM participating in the STD screening program in 2010.

Methods MSM seeking services at a variety of clinical sites provided clinician-collected pharyngeal specimens for APTIMA Combo 2 testing. The prevalence of pharyngeal CT and GC was estimated at five sentinel sites-the municipal STD clinic, a gay men's health clinic, an HIV care clinic, an HIV testing site, and primary care clinics supported by the San Francisco Department of Public Health. Positivity for each infection was calculated as the number of positive tests divided by the number of testers with corresponding CIs. Additionally, we calculated positivity and OR to determine whether the prevalence of pharyngeal CT and GC differed by HIV status among patients tested at the municipal STD clinic.

Results In 2010, over 12000 pharyngeal specimens were tested for an overall CT positivity of $1.69 \%$ (95\% CI 1.47 to 1.93$)$ and GC positivity of $5.76 \%$ ( $95 \%$ CI 5.36 to 6.19 ). At the five sentinel sites, pharyngeal CT positivity ranged from $1.10 \%$ (HIV testing site) to $2.28 \%$ (STD clinic); pharyngeal GC positivity ranged from $3.4 \%$ (HIV testing site) to $7.01 \%$ (STD clinic). For tests conducted at the STD clinic among HIV-uninfected testers, pharyngeal CT positivity was $1.57 \%$ (95\% CI 1.11 to 2.15 ) and pharyngeal GC positivity was $7.02 \%$ (95\% CI 6.03 to 8.11). Among HIV-infected testers, the pharyngeal CT and GC positivity were $4.06 \%$ (95\% CI 2.92 to 5.49 ) and $6.99 \%$ (95\% CI 5.48 to 8.76), respectively. HIV-infected testers were more likely to have a positive pharyngeal CT test compared with HIV-uninfected testers (OR 2.65, 95\% CI 1.65 to 4.27); there were no differences in pharyngeal GC positivity between HIVinfected and HIV-uninfected testers at the STD clinic.

Conclusion Sentinel surveillance data indicates that there is a substantial burden of pharyngeal CT and GC infections among MSM in San Francisco. Identification and treatment of pharyngeal infections could prevent ongoing transmission of these bacteria. Increasing access to NAAT-based pharyngeal screening should be a public health priority.

\section{P1-S2.42 STI PREVALENCE AND CONDOM USE IN MEN WHO HAVE SEX WITH MEN ATTENDING STI SERVICES, HONDURAS 2010}

doi:10.1136/sextrans-2011-050108.99

${ }^{1} \mathrm{~F}$ Tinajeros, ${ }^{1} \mathrm{~N}$ Artiles, ${ }^{1} \mathrm{~N}$ Farach, ${ }^{2} \mathrm{~L}$ Castro, ${ }^{2} \mathrm{~V}$ Maradiaga, ${ }^{3} \mathrm{~A}$ Sevilla, ${ }^{4} \mathrm{~S}$ Mendoza, ${ }^{5} \mathrm{M}$ Urquia, ${ }^{5} \mathrm{H}$ Galindo, ${ }^{6} \mathrm{G}$ Paz-Bailey. ${ }^{1}$ TEPHINET, Tegucigalpa, Honduras; ${ }^{2}$ Alonso Suazo Clinic, Tegucigalpa, Tegucigalpa, Honduras; ${ }^{3}$ Miguel Paz Barahona Clinic, San Pedro Sula, San Pedro Sula, Honduras; ${ }^{4}$ STI National Laboratory, Honduras, Tegucigalpa, Honduras; ${ }^{5}$ Ministry of Health, National AIDS Program, Tegucigalpa, Honduras; ${ }^{6}$ TEPHINET, Del Valle University of Guatemala, Guatemala

Background Men who have sex with men and the transgender population have the highest prevalence of HIV in Honduras. Specialised services for MSM were established at three public clinics in San Pedro Sula, La Ceiba and Tegucigalpa, with the objective of improving STI management and access to HIV testing and counselling among MSM and transgender populations. STI and HIV testing and management were strengthened at three STI clinics in early 2010. Health workers were trained on HIV/STI services, including counselling and reducing stigma and discrimination.

Methods Discussions with MSM organizations were carried out to determine the type of clinical and counselling services as well as a referral strategy for MSM. A standardised form was designed and implemented to collect key clinical, laboratory and behavioural indicators and entered into an electronic system in Epi-Info. The diagnostic tests offered at no charge were-rapid test and ELISA for HIV, PACE II for Chlamydia trachomatis and Neisseria gonorrhoeae, and RPR with TPPA for syphilis. All men attending the clinics in 2010 were included in this analysis. 
Results Between January and December 2010, 227 MSM received STI services in the VICITS clinics in Tegucigalpa, San Pedro Sula and La Ceiba. Patients' mean age was 27.4 years. Overall 60.8\% (135/222) reported alcohol use and $34.7 \%$ (76/219) reported drug use during the last year. An STI in the previous 12 months was reported by $37.6 \%$ $(83 / 221)$ and $13.6 \%(30 / 219)$ reported engaging in sex work. Out of those patients who reported engaging in sex work, $86.5 \%(94 / 109)$ used a condom during their most recent sexual encounter, $88.3 \%$ (147) 166) reported using a condom with casual partners and $64.5 \%$ (74/ $115)$ with stable partners. Overall, $12.3 \%(10 / 81)$ were infected with HIV, $10.3 \%(13 / 126)$ had a confirmed syphilis infection, 3.6\% (5/138) were infected with chlamydia and gonorrhoea.

Conclusions Results from the first year of STI clinics for MSM evidence high HIV and syphilis prevalence rates. Behaviour change interventions targeting this community should focus on increasing condom use. Efforts should be made to increase the number of MSM attending specialised services.

\section{P1-S2.43 BEHAVIOURAL AND BIOLOGICAL SURVEILLANCE AMONG MAN WHO HAVE SEX WITH MAN USING RESPONDENT- DRIVEN SAMPLING METHODOLOGY IN MANAUS, AMAZON, BRAZIL}

\section{doi:10.1136/sextrans-2011-050108.100}

${ }^{1} \mathrm{~A} S$ Benzaken, ${ }^{2} \mathrm{E}$ G Galban, ${ }^{3} \mathrm{~N}$ S Benzaken, ${ }^{4} \mathrm{C} \mathrm{K},{ }^{5} \mathrm{~A}$ Pinho, ${ }^{6} \mathrm{M}$ Mello, ${ }^{1} \mathrm{~F}$ Vasquez, ${ }^{1} \mathrm{C}$ A Barros, ${ }^{7} \mathrm{~L}$ R Franco Sansigolo Kerr. ${ }^{1}$ Alfredo da Matta Foundation, Manaus, Brazil; ${ }^{2}$ Instituto Nacional de Gastroenterologia, Habana, Cuba; ${ }^{3}$ Nilton Lins University, Brazil; ${ }^{4}$ Tulane University, School of Public Health and Tropical Medicine, New Orleans, USA; ${ }^{5}$ Escola Nacional de Saùde Publica, Brazil; ${ }^{6}$ CDC, Brazil, Brazil; ${ }^{7}$ Uversidade Federal do Ceará, Brazil

Background There is a renewed interest in including men who have sex with men (MSM) in global HIV surveillance. A multicenter study of 10 Brazilian cities was designed to generate a national-level estimate the prevalence of HIV and syphilis among MSM. This abstracts presents the results of one of the participating cities.

Objectives To establish a baseline among MSM in Manaus to continuously monitor the prevalence of HIV and syphilis infection, level of knowledge about STI/HIV/AIDS, prevailing sexual attitudes and practices, and frequency of acts of discrimination against MSM. Methodology A cross-sectional study of 824 MSM (>18 years old) was conducted from October to May 2008 using respondent-driven sampling (RDS)- a chain-link and snowball sampling method that generates probability-based samples and is systematic, so it can be used to develop comparable surveillance data.

Results The weighted prevalence obtained with the use of Respondent-Driven Sampling Analysis Tool (RDSAT) software were $6.8 \%$ (CI 4.9 to 9.8) for HIV and 4.0\% (CI 2.6 to 5.8) for syphilis. A number of participants reported sex with both men and women (47.8\% of HIV positive and $56.1 \%$ of syphilis cases), while $20 \%$ of HIV positive and $30 \%$ of syphilis cases classified themselves as gay or homosexual. A previous infection of syphilis was the main predictive variables associated with HIV. The average age of first intercourse was 13.25 (with a range 5-23). This pattern of early sex suggests abuse. Fifty four point five per cent of participants had their first sexual intercourse with men, $42.6 \%$ with women, and $2.2 \%$ with transvestites. Participants also reported-41\% (CI 37 to 47) used condoms in their first relationship, 73.1\% (CI 69.7 to 77.2 ) had at least one casual sex partner during the previous 12 months, $31.6 \%$ (CI 27.7 to 35.9 ) used condoms consistently with casual relationships if they were with men and $15.5 \%$ (CI 11.9 to 18.9) with a woman. Nineteen per cent of MSM said they had been the target of direct physical aggression due to their sexual identity, 10\% reported being forced to have sex against their will, and over $30 \%$ reported being humiliated or disrespected because of their sexual orientation.
Conclusions The prevalence of HIV and syphilis infection in MSM in the city of Manaus is relatively high. There is substantial discrimination against MSM. The need of specific public policy and awareness campaigns for this vulnerable group is urgent.

\section{P1-S2.44 TRENDS IN STI IN MSM VISITING DUTCH STI CENTRES; DOES AGE MATTER?}

doi:10.1136/sextrans-2011-050108.101

${ }^{1} \mathrm{~F}$ Koedijk, ${ }^{2} \mathrm{P}$ van Beek, ${ }^{2} \mathrm{~K}$ Koops, ${ }^{1,3} \mathrm{M}$ A B van der Sande, ${ }^{4}$ On behalf of the Dutch STI centres. ${ }^{1}$ National Institute for Public Health and the Environment, Bilthoven, Netherlands; ${ }^{2}$ Schorer, Netherlands' institute for homosexuality, health and well-being, Netherlands; ${ }^{3}$ Academic Medical Centre Utrecht, University of Utrecht, Utrecht, the Netherlands, Netherlands; ${ }^{4} A$ v Daal (East), P v Leeuwen (North-Holland Flevoland), F de Groot (North), A Niekamp (Limburg), M Langevoort (Utrecht), A v Camerijk (SouthHolland North),J vd Sande (ZeeBRa),E vd Veen (South-Holland South), Netherlands

Objectives This study examined the distribution of selected sexually transmitted infections (STI) in men and men having sex with men (MSM) attending STI clinics in the Netherlands, separately for young ( $\geq 25$ years) and older ( $>25$ years) MSM.

Methods Data from 2004 up to June 2010 from the Dutch national surveillance in the STI centres were used to characterise trends in positivity rate in STI (at least one of the following-chlamydia, gonorrhoea, syphilis or HIV). Logistic regression was used to identify factors associated with STI positivity in both groups.

Results Older MSM tested more often positive for STI than younger MSM-21.5\% vs $18.4 \%$, respectively $(p<0.05)$. However, in older MSM there was a significant decreasing time trend in STI positivity (from 23\% in 2004 to 19\% in 2010, p<0.05, abstract P1-S2.44 figure 1), while in young MSM the STI positivity rate remained stable over time. In multivariate analyses for young MSM, non-Dutch MSM tested significantly more often positive (OR $1.4,95 \%$ CI 1.3 to 1.6), as did those with a previous STI (OR 1.9, 95\% CI 1.6 to 2.1 ), known HIV positives (OR 3.1, 95\% CI 2.3 to 4.2), sex workers (OR 1.2, 95\% CI 1.1 to 1.6) and those with a low socio-economic status (OR 1.5, $95 \%$ CI 1.2 to 1.9). In older MSM, also non-Dutch MSM tested significantly more often positive (OR $1.2,95 \%$ CI 1.1 to 1.2 ), as did those with a previous STI (OR 1.6, 95\% CI 1.5 to 1.7), known HIV positives (OR 1.9, 95\% CI 1.8 to 2.1 ) and those with a low socioeconomic status (OR 1.2, 95\% CI 1.1 to 1.3). In contrast with young MSM, older MSM working as sex workers were at significantly lower risk (OR $0.7,95 \%$ CI 0.6 to 0.9 ) for testing positive for any STI.

Conclusions Young MSM are a specific group within total group of MSM, with some risk factors differencing from older MSM. While trends in positivity are decreasing over time in older MSM, they remain stable and high in young MSM. Therefore special attention needs to be paid towards counselling and reaching (specific groups of) young MSM, since they are at high risk for STI acquisition and transmission.

\section{P1-S2.45 CLUSTERS OFNEISSERIA GONORRHOEAE INFECTED PATIENTS ARE NOT LINKED TO HIV INFECTION WITHIN THE HOMOSEXUAL POPULATION IN AMSTERDAM, THE NETHERLANDS}

doi:10.1136/sextrans-2011-050108.102

R Heymans, S Bruisten, A Matser, T Heijman, $\mathrm{H}$ de Vries, M S van der Loeff. Health Service of Amsterdam, (GGD), Amsterdam, Netherlands

Background Sexual risk behaviour increased since the introduction of antiretroviral treatment against HIV-1. Consequently, since the 